\title{
Adverse events in deceased hospitalised cancer patients as a measure of quality and safety in end-of-life cancer care
}

\author{
Ellinor Christin Haukland ${ }^{1,2^{*}}$ (D), Christian von Plessen ${ }^{3,4,5}$, Carsten Nieder ${ }^{1,6}$ and Barthold Vonen ${ }^{2,7}$
}

\begin{abstract}
Background: Anticancer treatment exposes patients to negative consequences such as increased toxicity and decreased quality of life, and there are clear guidelines recommending limiting use of aggressive anticancer treatments for patients near end of life. The aim of this study is to investigate the association between anticancer treatment given during the last 30 days of life and adverse events contributing to death and elucidate how adverse events can be used as a measure of quality and safety in end-of-life cancer care.

Methods: Retrospective cohort study of 247 deceased hospitalised cancer patients at three hospitals in Norway in 2012 and 2013. The Global Trigger Tool method were used to identify adverse events. We used Poisson regression and binary logistic regression to compare adverse events and association with use of anticancer treatment given during the last 30 days of life.

Results: 30\% of deceased hospitalised cancer patients received some kind of anticancer treatment during the last 30 days of life, mainly systemic anticancer treatment. These patients had 62\% more adverse events compared to patients not being treated last 30 days, 39 vs. 24 adverse events per 1000 patient days $(p<0.001$, OR 1.62 (1.23-2.15). They also had twice the odds of an adverse event contributing to death compared to patients without such treatment, 33 vs. 18\% ( $p=0.045$, OR 1.85 (1.01-3.36)). Receiving follow up by specialist palliative care reduced the rate of AEs per 1000 patient days in both groups by $29 \%$ ( $p=0.02$, IRR 0.71, Cl 95\% 0.53-0.96).

Conclusions: Anticancer treatment given during the last 30 days of life is associated with a significantly increased rate of adverse events and related mortality. Patients receiving specialist palliative care had significantly fewer adverse events, supporting recommendations of early integration of palliative care in a patient safety perspective.
\end{abstract}

Keywords: Adverse event, End of life, Palliative care, Global trigger tool, Patient safety

\section{Background}

Effectiveness and safety are essential elements of value-based cancer care that need to be considered when making decisions about treatment during the entire continuum of the disease [1-3]. Striking the right balance between the two is a major clinical challenge, especially when the disease

\footnotetext{
* Correspondence: ellinor.haukland@nlsh.no

'Department of Oncology and Palliative Medicine, Nordland Hospital Trust, PO Box 1480, 8092 Bodø, Norway

${ }^{2}$ Institute of Community Medicine, The Arctic University of Norway, PO Box 6, 9038 Tromsø, Norway

Full list of author information is available at the end of the article
}

progresses towards the end of life. At this stage discontinuing anticancer treatment is one of five recommendations to reduce unnecessary treatment and increase the value of healthcare for patients with advanced cancer $[4,5]$.

Survival is of critical concern for cancer patients, but near the end of life the quality of care and how patients spend their remaining time is just as important $[6,7]$. Nevertheless, up to one out of five cancer patients receives anticancer treatment during the last 30 days of life without clear benefit of prolonging survival. The treatment also exposes them to the risk of severe negative 
consequences such as increased toxicity and decreased quality of life [8-10]. A meta-analysis of the efficacy and safety of anticancer treatment compared to palliative care found no difference in overall survival and significantly more severe adverse events among patients receiving anticancer treatment during the last 30 days of life [11]. This emphasises the need not to focus just on survival, but also the need to assess symptoms, toxicities and complications of anticancer treatment by systematically measuring adverse events [12].

Today, quality measures for end-of-life cancer care generally examine utilisation of healthcare services and use of systemic anticancer treatment, radiotherapy and specialist palliative care during the last month of life [13-15]. Although severe adverse events in cancer care are considered an important outcome measure with high clinical value, current measurements do not include adverse events as an indication of quality and safety in end-of-life cancer care [16].

Thus, the objectives of our study is to investigate the association between anticancer treatment given during the last 30 days of life and adverse events contributing to death and see if adverse events can be used as a measure of quality and safety in end-of-life cancer care.

\section{Methods}

\section{Study design}

The study is a retrospective cohort study of deceased hospitalised cancer patients. We performed a standardised retrospective record review using the Global Trigger Tool (GTT) to identify adverse events contributing to death related to anticancer treatment given during the last 30 days of life.

\section{Setting}

The study was conducted at a public health trust in Northern Norway, providing healthcare to a population of 136,000 inhabitants. Nordland Hospital Trust is a public health trust with three general hospitals; one central teaching hospital and two smaller district hospitals. Cancer patients are treated and hospitalised in all three hospitals, but only the central hospital has a separate oncology and haematology department providing ambulatory chemotherapy and palliative radiotherapy. All three hospitals has a specialist palliative care team providing both inpatient and ambulatory care to patients referred to them. None of the hospitals has a separate oncological inpatient unit. Accordingly, the primary care of hospitalised cancer patients is provided by other specialists (e.g. internist, surgeon and neurologist) depending on the origin of the cancer, who then consults an oncologist or palliative care if needed.

\section{Study population}

The cohort includes all cancer patients with solid tumours and haematological malignancies, 18 years or older who died in one of the three hospitals. Since there were no previous studies indicating incidence rates of adverse events contributing to death in this selected population we did a consecutive sampling of all cancer patients who died in the three hospitals between January 1st 2012 and December 31st 2013. Of the 737 deceased hospitalised patients, 16 children under the age of 18 years were excluded. 247 (34\%) patients had cancer as primary or secondary diagnosis on discharge classified by the ICD-10 system. These cancer patients were divided into one group that had received any kind of anticancer treatment and a second group that had not received any anticancer treatment during the last 30 days of life. From the electronic patient records we obtained baseline demographics such as age, gender, length of stay, hospital, department, primary and secondary diagnosis on discharge. We also reviewed the patient records for the type of cancer, presence of metastases, setting (diagnostic, curative or palliative), the last date of administration of parenteral or oral anticancer treatment (chemotherapy, targeted agents and immune therapy), the use of radiotherapy and cancer directed surgery, as well as the date for involvement of specialised palliative care.

\section{Retrospective review}

During 6 months in 2015, a team of two oncology nurses and one oncologist did a structured review of the patient records. The review was conducted according to the Norwegian version of the Institute of Healthcare Improvement GTT manual $[17,18]$. The method is a twostage process where the nurses independently review all records using triggers to identify adverse events. To the 48 general triggers, we added 21 specific oncology triggers developed by the 1000 Lives Plus Campaign in Wales, UK [19]. The two nurses independently identified the presence, category and severity of the AEs, before they discussed their findings with the oncologist and together reached consensus. To validate the results, two other physicians independently re-reviewed the records of adverse events contributing to death and confirmed/ rejected the adverse event, severity and type of harm.

\section{Definition and classification of adverse events}

We defined an adverse event as: "Unintended physical injury resulting from or contributed to by medical care that requires additional monitoring, treatment or hospitalization, or that results in death" [18]. The severity of AEs was categorised according to the NCC MERP index [20]. Adverse events were recorded into six main categories: healthcare acquired infections, surgical complications, bleeding/thrombosis, medication harm, pressure ulcer and others. For 
medication-related adverse events, the generic name was documented.

\section{Statistical analysis}

We summarised the data using descriptive statistics and compared the groups using the Mann-Whitney $\mathrm{U}$ test for non-parametric continuous variables, and the Chi square, Fisher's exact or Linear-by-Linear test for categorical variables. There were no missing data. Incidence rates of adverse events, severities and categories of adverse events were compared using Poisson regression for generalised linear models. Binary logistic regression was used to analyse if adverse events were significantly associated with use of anticancer treatment during the last 30 days of life. Adverse events contributing to death were set as the dependent variable, while use of systemic anticancer treatment during the last 30 days of life was included as a dichotomous explanatory variable. Building a model we first assessed which variables were a potential confounder, before we adjusted for length of stay, age, gender and primary malignancies. To reduce the probability of Type I errors (Bonferronis` correction) the number of variables included were limited to five. A pvalue of $<0.05$ was considered significant. We used the statistical package IBM SPSS Statistics V.25.0 to analyse the data.

\section{Results}

\section{Patient characteristics}

Most patients had advanced cancer and were in a palliative care setting. Sixty percent of the patients received some kind of anticancer treatment, mainly systemic anticancer treatment. Patients receiving treatment during the last 30 days of life had a longer length of stay and were more often admitted to the central hospital. Patients with lung cancer, lymphoma and haematological malignancies were more likely to receive treatment during the last 30 days of life. Table 1 compare characteristics between patients receiving anticancer treatment during the last 30 days of life with patients not receiving such treatment.

\section{Treatment during the last $\mathbf{3 0}$ days of life}

Anticancer treatment of any kind was given to $30 \%$ of patients during the last 30 days of life. Treatment given during the last 30 days was mainly systemic anticancer treatment $(21 \%)$. In addition, $8.5 \%$ of the patients received radiotherapy during the last 30 days of life, where of more than half during the last 10 days of life. Specialised palliative care was provided equally to both groups, 34 vs. $37 \%$ (Table 1$)$.

\section{Adverse events}

Patients receiving anticancer treatment during the last 30 days of life had $46 \%$ more adverse events than patients not treated during the last 30 days of life, 82 vs. 56 adverse events per 1000 patient days $(p<0.01$, RR 1.46, CI 95\% 1.10-1.94). Patients receiving treatment during the last 30 days of life experienced more temporary adverse events (severity $\mathrm{E}$ and $\mathrm{F}$ ), 25 vs 16 adverse events per 1000 patient days (RR 1.61, $p=0.07$ CI 95\% 1.142.27). They also more severe adverse events contributing to death (severity I), 11 vs. 6 adverse events per 1000 patient days, (RR 1.84, $p=0.024$ CI 95\% 1.08-3.14) (Fig. 1). Patients in both groups receiving specialist palliative care had significantly fewer adverse events than patients not referred to palliative care, 52 vs. 73 adverse events per 1000 patient days (RR $0.71, p=0.02$ CI 95\% 0.53-0.96).

\section{Types of adverse event}

The most common types of adverse events were healthcare-acquired infections and medication related adverse events (Fig. 2). There was no difference in the rate of healthcare-acquired infections, surgical complications, pressure ulcers or others between the groups. $\mathrm{Pa}$ tients receiving treatment during the last 30 days of life had significantly higher rates of medication related adverse events, 21 vs. 9 adverse events per 1000 patient days ( $p<0.001$, RR 2.35, CI 95\% 1.55-3.58). Twenty-four percent of patients receiving systemic anticancer treatment had an adverse event related to the treatment. Bleeding or thrombosis also occurred more often in patients receiving treatment during the last 30 days, 5 vs. 2 adverse events per 1000 patient days $(p=0.003$, RR 2.62, CI 95\% 1.09-6.34). For more detailed description of types of adverse events see supplementary materials.

\section{Adverse events contributing to death}

An adverse event contributed to death in $22 \%$ of all deceased hospitalised cancer patients. Patients receiving anticancer treatment during the last 30 days of life experienced nearly double the rate of adverse events contributing to death compared to patients not being treated during the last month of life, 33 vs. $18 \%(p=$ 0.045 , adjusted OR 1.85, CI 95\% 1.014-3.359). Table 2 presents unadjusted and adjusted results of the association between anticancer treatment given last 30 days of life and adverse events contributing to death. Adverse events contributing to death were mainly medication harms and healthcare acquired infections. Systemic anticancer treatment contributed to death in $11 \%$ of patients receiving systemic anticancer treatment, all given during the last 30 days of life. For patients not receiving treatment during the last 30 days of life, healthcare acquired infections contributed to death for $58 \%$ of the patients. An adverse event 
Table 1 Characteristics

\begin{tabular}{|c|c|c|c|c|c|}
\hline \multirow[t]{2}{*}{ Variable } & \multicolumn{2}{|c|}{ No anticancer treatment last 30 days $\boldsymbol{n}=174$} & \multicolumn{2}{|c|}{ Anticancer treatment given last 30 days $\boldsymbol{n}=73$} & \multirow[t]{2}{*}{$P$ value ${ }^{a}$} \\
\hline & $n$ & $\%$ & $n$ & $\%$ & \\
\hline Age (years) - median (min - max) & 72 & $(18-93)$ & 74 & $(40-91)$ & NS \\
\hline Length of stay (days) - median (min - max) & 8 & $(0-84)$ & 12 & $(0-68)$ & 0.03 \\
\hline Gender & & & & & NS \\
\hline Female & 68 & $39 \%$ & 28 & $38 \%$ & \\
\hline Male & 106 & $61 \%$ & 45 & $62 \%$ & \\
\hline Hospital & & & & & $<0.01$ \\
\hline District Hospital Lofoten & 27 & $16 \%$ & 6 & $8 \%$ & \\
\hline District Hospital Vesterålen & 47 & $27 \%$ & 11 & $15 \%$ & \\
\hline Central Hospital Bodø & 100 & $57 \%$ & 56 & $77 \%$ & \\
\hline Department & & & & & NS \\
\hline Internal medicine & 76 & $44 \%$ & 44 & $60 \%$ & \\
\hline Surgery & 91 & $52 \%$ & 25 & $34 \%$ & \\
\hline Others & 7 & $4 \%$ & 4 & $6 \%$ & \\
\hline Primary malignancy & & & & & 0.02 \\
\hline Upper gastrointestinal & 34 & $20 \%$ & 5 & $7 \%$ & \\
\hline Colorectal & 27 & $15 \%$ & 4 & $5 \%$ & \\
\hline Lung & 38 & $22 \%$ & 21 & $29 \%$ & \\
\hline Breast & 7 & $4 \%$ & 4 & $5 \%$ & \\
\hline Gynaecological & 5 & $3 \%$ & 2 & $3 \%$ & \\
\hline Urological & 8 & $5 \%$ & 6 & $8 \%$ & \\
\hline Male genitalia & 11 & $6 \%$ & 4 & $5 \%$ & \\
\hline Haematological and lymphoma & 17 & $10 \%$ & 22 & $30 \%$ & \\
\hline Unknown origin & 15 & $8 \%$ & 2 & $3 \%$ & \\
\hline Other ${ }^{b}$ & 12 & $7 \%$ & 3 & $4 \%$ & \\
\hline Treatment intent & & & & & $<0.001$ \\
\hline Palliative & 135 & $78 \%$ & 67 & $92 \%$ & \\
\hline Curative & 2 & $1 \%$ & 3 & $4 \%$ & \\
\hline Diagnostic & 37 & $21 \%$ & 3 & $4 \%$ & \\
\hline Anticancer treatment & & & & & $<0.001$ \\
\hline Systemic treatment & 64 & $37 \%$ & 52 & $71 \%$ & \\
\hline Radiotherapy & 5 & $3 \%$ & 14 & $19 \%$ & \\
\hline Surgery & 5 & $3 \%$ & 7 & $10 \%$ & \\
\hline No treatment & 100 & $57 \%$ & 0 & $0 \%$ & \\
\hline Specialist palliative care & & & & & NS \\
\hline$>30$ days before death & 33 & $19 \%$ & 11 & $15 \%$ & \\
\hline$<30$ days before death & 32 & $18 \%$ & 14 & $19 \%$ & \\
\hline Not involved & 109 & $63 \%$ & 48 & $66 \%$ & \\
\hline
\end{tabular}

${ }^{a}$ The $p$ value measures the difference between the two groups and was set to 0.05 . NS not significant

${ }^{b}$ The group consist of patients with cancer from head-neck, sarcoma, malignant melanoma, eye and CNS

contributed to death more commonly in patients with lymphoma and haematological malignancies, 27 vs. $13 \%,\left(p=0.025, \mathrm{~S}_{\mathrm{res}} 2.1\right)$. Radiotherapy did not contribute to the death of any patient.

\section{Discussion}

There are clear guidelines recommending limiting use of aggressive anticancer treatments for cancer patients near end of life $[4,12]$. Still we found that one third of 


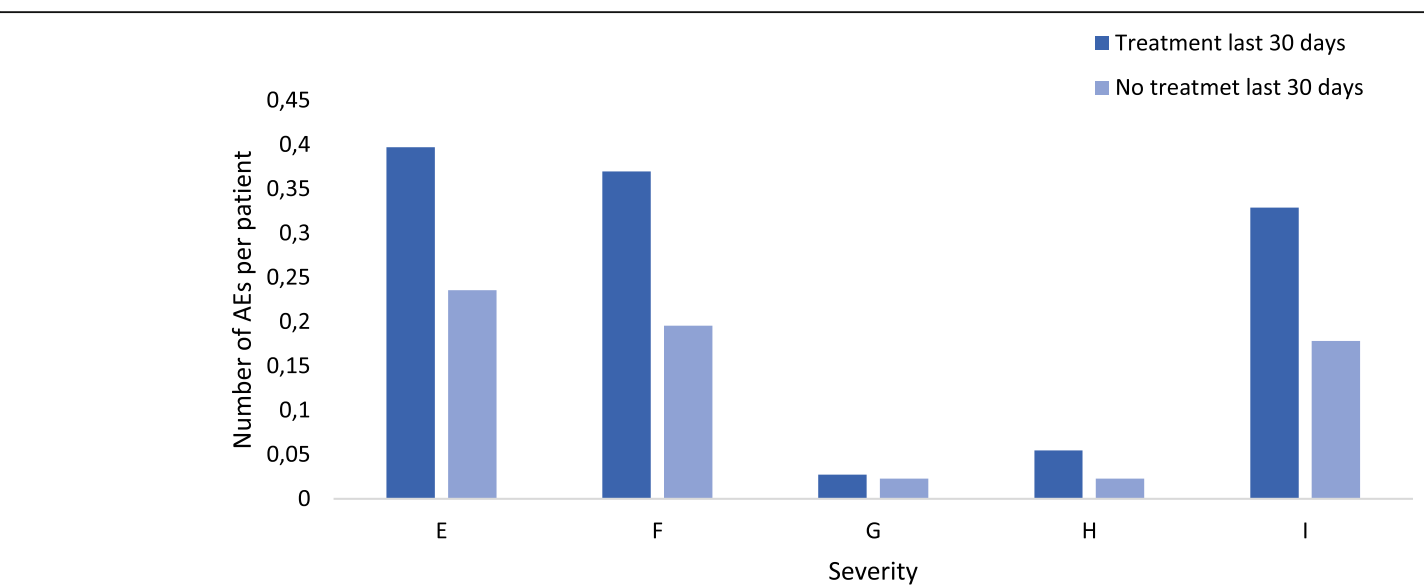

Fig. 1 Severity of adverse events per patient categorised according to the NCC MERP Index. Comparing severity of adverse events between patient receiving or not receiving anticancer treatment during the last 30 days of life. Category E: temporary harm that required intervention. Category F: temporary harm that required initial or prolonged hospitalisation. Category G: permanent patient harm. Category H: intervention required necessary to sustain life. Category I: harm contributes to patient death

deceased hospitalised cancer patients received some kind of anticancer treatment during the last 30 days of their lives. Patients receiving anticancer treatment during the last 30 days of life also had an increased rate of adverse events compared to cancer patients not given treatment in this period. Most of the adverse events were temporary harms requiring medical intervention, often initiating or prolonging hospitalisation (severity $\mathrm{E}$ and F). Even less severe adverse events can cause an extra burden of harm and reduce the quality of life during the limited remaining time, when many patients prefer to be at home with their families [6, 21].

We found that one in five deceased hospitalised cancer patients had an adverse event contributing to death. This included all types of adverse events whether caused by systemic anticancer treatment, other medications or healthcare acquired infections. In a previous study we found that hospitalised cancer patients had an increased risk of adverse events in general compared to other hospitalised patients, and that they more often experienced adverse events related to medications [22].

Our findings are higher than those of registry studies showing that $4-27 \%$ of cancer patients die as a complication of anticancer treatment, but these studies do not specifically investigate occurrence of adverse events [14, $15,23]$. We also found that patients receiving anticancer treatment during the last 30 days had twice the odds of having an adverse event contributing to death compared

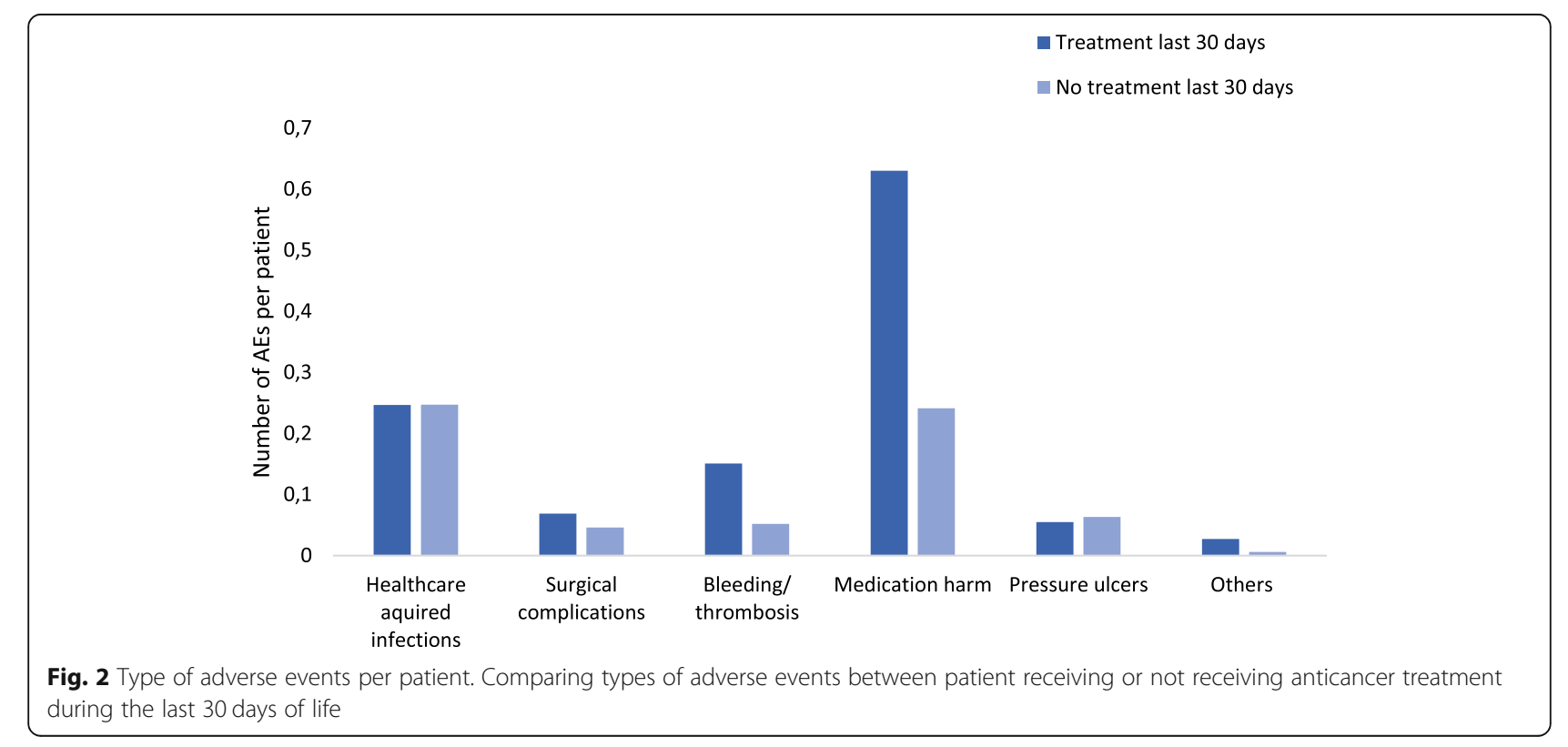


Table 2 Association between anticancer treatment given last 30 days of life and adverse events contributing to death

\begin{tabular}{|c|c|c|c|c|}
\hline Variables & AE contributing to death & OR & $95 \% \mathrm{Cl}$ & $P$ value \\
\hline 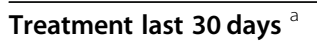 & $32.9 \%$ & 2.26 & $1.211-4.216$ & 0.01 \\
\hline No treatment last 30 days & $17.8 \%$ & & & \\
\hline Treatment last 30 days ${ }^{b}$ & & 1.85 & $1.014-3.359$ & 0.045 \\
\hline Age & & 0.97 & $0.938-0.995$ & 0.021 \\
\hline Length of stay & & 0.98 & $0.984-0.962$ & 0.184 \\
\hline Gender & & 1.84 & $0.935-3.623$ & 0.047 \\
\hline Type cancer & & & & 0.145 \\
\hline Gastrointestinal & & 0.98 & $0.370-2.599$ & 0.968 \\
\hline Respiratory & & 0.68 & $0.181-2.516$ & 0.559 \\
\hline Breast and gynaecology & & 0.37 & $0.130-1.027$ & 0.056 \\
\hline Urinary & & 0.35 & $0.132-0.934$ & 0.036 \\
\hline Haematological & & 0.75 & $0.244-2.280$ & 0.607 \\
\hline Others & & & & \\
\hline
\end{tabular}

Binary logistic regression analyses presenting ${ }^{a}$ unadjusted and ${ }^{b}$ adjusted results

to patients without such treatment. Considering that an adverse event can often be one of many factors contributing to death, it could be that receiving treatment in the last 30 days of life adds yet another layer of treatment related adverse events with an increased risk of hastening death.

Nearly one third of our deceased hospitalised cancer patients received some kind of anticancer treatment during the last 30 days of life, mainly systemic anticancer treatment. Similarly to other studies we found that patients receiving treatment during the last 30 days of life had a longer length of stay, were treated at larger hospitals and more often had lung cancer, lymphoma or haematological malignancies [24-28]. In other studies, the use of anticancer treatment during the last 30 days of life varied from 6 to $43 \%$, depending on country and patients included [29-31]. Our results are consistent with similar studies including all types of malignancies $[15,32]$, but the rates are higher than in registry studies of solid tumours indicating that Norway has among the lowest (6-10\%) use of systemic anticancer treatment during the last 30 days of life in Europe [23, 29]. Thus comparison of the results can be problematic due to differences in study design and included population [13].

Similar to other studies we find that medication harms and healthcare acquired infections were the most common adverse events [22, 33], but their occurrences differed between the groups. While healthcare acquired infections contributed to death of cancer patients in both groups, anticancer treatment related adverse events, contributing to death only occurred in patients who received such treatment during the last 30 days of life. Consequently, when measuring anticancer treatment related adverse events contributing to death we can be more pragmatic and limit the inclusion to deceased hospitalised patients treated during the last 30 days of life.
It is rarely straightforward to argue that anticancer treatment is the direct cause of death. Most likely, reduced functional status, malnutrition and immunosuppression amplify adverse events related to anticancer treatment and increase the negative impact on the patients` remaining lifetime [34]. Our study is not designed to investigate if these treatment-related adverse events affects survival, but nevertheless our results indicate that systemic anticancer treatment given during last 30 days of life can hasten the death of patients.

The proportion of patients treated with radiotherapy during the last 30 days of life in our study, was similar to the results of other studies [23,35]. While radiotherapy in contrast to systemic anticancer treatment did not contribute to any deaths in our study, it still must be considered of little benefit when given during the last 30 days of life. The benefit of radiotherapy near end of life is questionable with only one out of four patients reporting symptom relief [36]. Patients receiving radiotherapy are also more often hospitalised and die in hospitals [23, 35]. Nearly half of our patients received radiotherapy during the last 10 days of life, which must be considered futile and a misuse of the patients' time and focus. Radiotherapy can provide needed palliation to patients with advanced cancer, but fractionation regimes should reflect life expectancy and sometimes it is better to provide palliative relief in other ways.

Early referral to palliative care is associated with improved quality of life, fewer acute hospital admissions and less aggressive cancer treatment near the end of life [37-39]. Our findings indicate that patients receiving specialist palliative care had significantly fewer adverse events than patients not referred to palliative care. Symptom management is a key element of palliative care. Diagnosing and managing symptoms at an early 
stage can prevent them from developing into adverse events and thereby improve the patient safety for cancer patients. This supports recommendations of early integration also in a patient safety perspective. However, our study is not designed to determine if the reduction in adverse events is due to specialised palliative care or due to discontinuing of anticancer treatment.

Even though palliative care should be an integrated part of oncology, patients are often first referred to palliative care when anticancer treatment ends [40]. Knowing the positive associations for the quality of life and safety benefits for cancer patients referred to palliative care, the low referral rate (35\%) of deceased cancer patients is worrisome. Availability of specialist palliative care are equal to all cancer types at our hospital and the palliative care teams has regular follow up with all departments. Nevertheless, the culture for referral may vary between specialties. One reason for the low referral to palliative care could be the perception that palliative care is equal to end-of-life care. Since the study was conducted in 2012-2013 this perception has gradually changes and palliative care is increasingly actknowledged as an important part of good quality cancer care that should be integrated early in the course of disease [40].

Other reasons for low referral rates could be resources allocated to palliative care and a healthcare system consisting of silos, not structures to support the integration of palliative care across all specialties and throughout the whole continuum of cancer care. In so means, early referral to palliative care itself can be regarded as a relevant clinical measure of quality in cancer care.

Strength of our study is the completeness of the data. We have included all cancer patients who died during a two-year period at our hospitals. Norway has one of the highest rates of hospital deaths for cancer patients and cancer patients receiving treatment during the last 30 days of their lives are often hospitalised and die in hospital $[29,32]$. We therefore argue that our study population is representative of cancer patients cared for by a general hospital trust. But, given the considerable variations in oncology practice within and across countries, the generalizability of our finding can be debated [29]. The main limitation of our study is that it is from only one hospital trust in Norway.

Known limitations of retrospective record reviewing such as information bias and subjective judgments may also apply to our study. Conscious of these limitations we have used a standardised review method (GTT method) with high sensitivity and specificity compared to other methods detecting adverse events [41]. To address limitations with the method of poor to moderate reliability, the review was conducted by a consistent and experienced oncology team [42-44]. In addition, we assessed the validity of our findings by having two physicians independently re-review and verify adverse events contributing to death. We found good correlation between the reviewers, where the severity changed only once and type of adverse event changed twice. However, when studying the intensity and safety of end-of-life care a retrospective design has the advantage since we only know the exact period before death retrospectively. A retrospective design allows for easy identification of cohorts of relevant patients and avoidance of inclusion bias [45].

\section{Conclusion}

Anticancer treatment given during the last 30 days of life is associated with a significantly increased rate of adverse events with twice the odds of having an adverse event contributing to death. Patients receiving specialist palliative care had significantly fewer adverse events, supporting recommendations of early integration of palliative care in a patient safety perspective. Identifying these adverse events is clearly warranted to improve clinical practice and avoid overtreatment in end-of life cancer care. Doing so with a standardised review method on a limited number of deceased hospitalised cancer patients proved to be efficient, and can provide a pragmatic real time measure of quality and safety in end-of-life cancer care.

\section{Supplementary information}

Supplementary information accompanies this paper at https://doi.org/10. 1186/s12904-020-00579-0.

Additional file 1.

\section{Abbreviations}

GTT: Global Trigger Tool; NCC MERP: National Coordinating Council on Medical Error Reporting and Prevention

\section{Acknowledgements}

The authors would like to thank Trude Merethe Kristiansen and Siv-Heidi Simonsen as participants of the GTT review team. Thanks to Marthe Larsen for advice on statistical analysis, Alexander Ringdal, Elisabeth Mentzoni and Marina Mineeva for help with data processing.

\section{Authors' contributions}

$\mathrm{ECH}$ and $\mathrm{BV}$ designed the study. ECH led the review and collection of data. $\mathrm{ECH}$, supervised by BV analysed the data. ECH, BV, CVP and CN together interpreted the data. ECH led the writing of the paper, while all the other authors contributed to revising the manuscript. All authors contributed substantially to the writing of the paper, and all reviewed and approved the final draft.

\section{Funding}

E. Haukland receives a PhD grant from the Northern Norway Regional Health Authority (HST1195-14), otherwise the funder has no practical role in this study. The publication charges for this article have been funded by a grant from the publication fund of The Arctic University of Norway.

\section{Availability of data and materials}

The datasets used and analysed during the current study are available from the corresponding author on reasonable request.

Ethics approval and consent to participate

The Regional Committee for Medical and Health Research Ethics, in Norway has reviewed the study and categorised it as retrospective health record 
research, which does not require approval by the committee. Reference number 2013/1823.

\section{Consent for publication}

Not applicable.

\section{Competing interests}

The authors declare that they have no competing interests.

\section{Author details}

'Department of Oncology and Palliative Medicine, Nordland Hospital Trust, PO Box 1480, 8092 Bodø, Norway. ${ }^{2}$ Institute of Community Medicine, The Arctic University of Norway, PO Box 6, 9038 Tromsø, Norway. ${ }^{3}$ Direction Générale de la Santé, Canton Vaud, Switzerland. ${ }^{4}$ Unisanté, Direction Générale de la santé, Avenue de Casèrnes 2, 1018 Lausanne, Switzerland. ${ }^{5}$ Institute for Clinical Research, University of Southern Denmark, Odense, Denmark. 'Institute of Clinical Medicine, The Arctic University of Norway, Tromsø, Norway. ${ }^{7}$ Centre for Clinical Documentation and Evaluation, Northern Norway Regional Health Authority, PO Box 6, 9038 Tromsø, Norway.

Received: 10 September 2019 Accepted: 18 May 2020

Published online: 01 June 2020

\section{References}

1. Institute of Medicine. Delivering High-Quality Cancer Care: Charting a New Course for a System in Crisis. Washington DC: The National Academies Press; 2013. https://doi.org/10.17226/18359.

2. Young RC. Value-Based Cancer Care. N Engl J Med. 2015;373:27. https://doi. org/10.1056/NEJMp1508387.

3. Goulart BHL. Value in Cancer care value: the next frontier in Cancer care Oncologist. 2016;21:651-3. https://doi.org/10.1634/theoncologist.2016-0174.

4. Schnipper LE, Smith TJ, Raghavan D, Blayney DW, Ganz PA, Mulvey TM, et al. American Society of Clinical Oncology identifies five key opportunities to improve care and reduce costs: the top five list for oncology. J Clin Oncol. 2012;30:1715-24. https://doi.org/10.1200/JCO.2010.33.1744.

5. Peppercorn JM, Smith TJ, Helft PR, DeBono DJ, Berry SR, Wollins DS, et al. American society of clinical oncology statement: toward individualized care for patients with advanced cancer. J Clin Oncol. 2011;29:755-60. https://doi. org/10.1200/JCO.2010.33.1744.

6. Higginson IJ, Gomes B, Calanzani N, Gao W, Bausewein C, Daveson BA, et al. Priorities for treatment, care and information if faced with serious illness: a comparative population-based survey in seven European countries. Palliat Med. 2014:28:101-10. https://doi.org/10.1177/0269216313488989.

7. Dalal S, Bruera E. End-of-life care matters: palliative Cancer care results in better care and lower costs. Oncologist. 2017;22:361-8. https://doi.org/10. 1634/theoncologist.2016-0277.

8. Braga S. Why do our patients get chemotherapy until the end of life? Ann Oncol. 2011;22:2345-8. https://doi.org/10.1093/annonc/mdr416.

9. Saito AM, Landrum M, Neville BA, Ayanian JZ, Earle CC. The effect on survival of continuing chemotherapy to near death. BMC Palliat Care. 2011; 10. https://doi.org/10.1186/1472-684x-10-14

10. Wright AA, Zhang B, Keating NL, Weeks JC, Prigerson HG. Associations between palliative chemotherapy and adult cancer patients' end of life care and place of death: prospective cohort study. BMJ. 2014;348:g1219. https:// doi.org/10.1136/bmj.g1219.

11. Reljic T, Kumar A, Klocksieben FA, Djulbegovic B. Treatment targeted at underlying disease versus palliative care in terminally ill patients: a systematic review. BMJ Open. 2017;7:e014661. https://doi.org/10.1136/ bmjopen-2016-014661.

12. Jordan K, Aapro M, Kaasa S, Ripamonti Cl, Scotté F, Strasser F, et al. European Society for Medical Oncology (ESMO) position paper on supportive and palliative care. Ann Oncol. 2018;29:36-43. https://doi.org/10. 1093/annonc/mdx757.

13. Luta $X$, Maessen M, Egger M, Stuck AE, Goodman D, Clough-Gorr KM. Measuring intensity of end of life care: a systematic review. PLoS One. 2015; 10:e0123764. https://doi.org/10.1371/journal.pone.0123764.

14. O'Brien MER, Borthwick A, Rigg A, Leary A, Assersohn L, Last K, et al. Mortality within 30 days of chemotherapy: a clinical governance benchmarking issue for oncology patients. Br J Cancer. 2006;95:1632-6. https://doi.org/10.1038/sj.bjc.6603498.
15. Mort D, Lansdown M, Smith N, Protopapa K, Mason M. For better, for worse? A review of the care of patients who died within 30 days of receiving systemic anti-cancer therapy. London; 2008. https://www.ncepod. org.uk/2008report3/Downloads/SACT_report.pdf. Accessed 19 Jun 2019.

16. Poortmans P, Banks I, Levy J, Meier K, Price R, Wiinberg L, et al. Understanding pragmatisk outcome measures in oncology. In: Building the roadmap to outcomes-based cancer care; 2018. https://www.ecco-org.eu/ Policy/ECCO-CODE-Project. Accessed 19 June 2019.

17. Norwegin Institute of Public Health; The Knowledge Centre for the Health Services. Structured journal review, using the GTT method to identify and measure incidence of harm in helath care. Oslo; 2010. https://www. pasientsikkerhetsprogrammet.no/målinger/global-trigger-tool-gtt. Accessed Jan 2014.

18. Griffin F, Resar R. IHI global trigger tool for measuring adverse events. 2nd ed: IHI Innovation Series white paper; 2009. http://www.ihi.org/resources/ Pages/IHIWhitePapers/IHIGlobalTriggerToolWhitePaper.aspx. Accessed Jan 2014

19. National Health Services. How to Use Trigger Tools. Wales; 2012. www.1 o00livesplus.wales.nhs.uk. Accessed 19 June 2019.

20. Hartwig SC, Denger SD, Schneider PJ. Severity-indexed, incident reportbased medication error-reporting program. Am J Hosp Pharm. 1991;48: 2611-6.

21. Wright AA, Keating NL, Ayanian JZ, Chrischilles EA, Kahn KL, Ritchie CS, et al. Family perspectives on aggressive cancer care near the end of life. JAMA. 2016;315:284-92. https://doi.org/10.1001/jama.2015.18604.

22. Haukland EC, von Plessen C, Nieder C, Vonen B. Adverse events in hospitalised cancer patients: a comparison to a general hospital population. Acta Oncol. 2017;56:1218-23. https://doi.org/10.1080/0284186X.2017. 1309063.

23. Anshushaug M, Gynnild MA, Kaasa S, Kvikstad A, Grønberg BH. Characterization of patients receiving palliative chemo- and radiotherapy during end of life at a regional cancer center in Norway. Acta Oncol. 2015; 54:395-402. https://doi.org/10.3109/0284186x.2014.948061.

24. Skov Benthien $K$, Adsersen M, Petersen MA, Soelberg Vadstrup E, Sjøgren $P$, Groenvold M. Is specialized palliative cancer care associated with use of antineoplastic treatment at the end of life? A population-based cohort study. Palliat Med. 2018;32:1509-17. https://doi.org/10.1177/ 0269216318786393

25. Henson LA, Gomes B, Koffman J, Daveson BA, Higginson IJ, Gao W. Factors associated with aggressive end of life cancer care. Support Care Cancer. 2015;24:1079-89. https://doi.org/10.1007/s00520-015-2885-4.

26. Hui D, Didwaniya N, Vidal M, Shin SH, Chisholm G, Roquemore J, et al. Quality of end-of-life care in patients with hematologic malignancies: a retrospective cohort study. Cancer. 2014;120:1572-8. https://doi.org/10.1002/ cncr.28614.

27. Rochigneux P, Raoul JL, Beaussant $Y$, Aubry R, Goldwasser F, Tournigand C, et al. Use of chemotherapy near the end of life: what factors matter? Ann Oncol. 2017;28:809-17. https://doi.org/10.1093/annonc/mdw654.

28. Earle CC, Landrum MB, Souza JM, Neville BA, Weeks JC, Ayanian JZ. Aggressiveness of cancer care near the end of life: is it a quality-of-care issue? J Clin Oncol. 2008;26:3860-6. https://doi.org/10.1200/JCO.2007.15.8253.

29. Bekelman JE, Halpern SD, Blankart CR, Bynum JP, Cohen J, Fowler R, et al. Comparison of site of death, health care utilization, and hospital expenditures for patients dying with cancer in 7 developed countries. JAMA. 2016;315:272-83. https://doi.org/10.1001/jama.2015.18603.

30. Cardona-Morrell M, Kim JCH, Turner RM, Anstey M, Mitchell IA, Hillman K. Non-beneficial treatments in hospital at the end of life: a systematic review on extent of the problem. Int J Qual Health Care. 2016:28:456-69. https:// doi.org/10.1093/intqhc/mzw060.

31. Choi Y, Keam B, Kim TM, Lee SH, Kim DW, Heo DS. Cancer treatment near the end-of-life becomes more aggressive: changes in trend during 10 years at a single institute. Cancer Res Treat. 2015;47:555-63. https://doi.org/10. 4143/crt.2014.200

32. Nappa U, Lindqvist $\mathrm{O}$, Rasmussen $\mathrm{BH}$, Axelsson B. Palliative chemotherapy during the last month of life. Ann Oncol. 2011;22:2375-80. https://doi.org/ 10.1093/annonc/mdq778.

33. Lipczak H, Knudsen JL, Nissen A. Safety hazards in cancer care: findings using three different methods. BMJ Qual Saf. 2011;20:1052-6. https://doi. org/10.1136/bmjqs.2010.050856.

34. Prigerson HG, Bao Y, Shah MA, Elizabeth Paulk M, LeBlanc TW, Schneider BJ, et al. Chemotherapy use, performance status, and quality of life at the end 
of life. JAMA Oncol. 2015;1:778-84. https://doi.org/10.1001/jamaoncol.2015. 2378.

35. Guadagnolo BA, Liao KP, Elting L, Giordano S, Buchholz TA, Shih YCT. Use of radiation therapy in the last 30 days of life among a large population-based cohort of elderly patients in the United States. J Clin Oncol. 2013;31:80-7. https://doi.org/10.1200/JCO.2012.45.0585.

36. Gripp S, Mjartan S, Boelke E, Willers R. Palliative radiotherapy tailored to life expectancy in end-stage cancer patients: reality or myth? Cancer. 2010;116: 3251-6. https://doi.org/10.1002/cncr.25112.

37. Temel JS, Greer JA, Muzikansky A, Gallagher ER, Admane S, Jackson VA, et al. Early palliative care for patients with metastatic non-small-cell lung cancer. N Engl J Med. 2010;363:733-42. https://doi.org/10.1056/NEJMoa1000678.

38. Zimmermann C, Swami N, Krzyzanowska M, Hannon B, Leighl N, Oza A, et al. Early palliative care for patients with advanced cancer: a clusterrandomised controlled trial. Lancet. 2014;383:1721-30. https://doi.org/10. 1016/50140-6736(13)62416-2.

39. Ziegler LE, Craigs CL, West RM, Carder P, Hurlow A, Millares-Martin P, et al. Is palliative care support associated with better quality end-of-life care indicators for patients with advanced cancer? A retrospective cohort study. BMJ Open. 2018;8. https://doi.org/10.1136/bmjopen-2017-018284.

40. Kaasa S, Loge JH, Aapro M, Albreht T, Anderson R, Bruera E, et al. Integration of oncology and palliative care: a lancet oncology commission. Lancet Oncol. 2018;19:e588-653. https://doi.org/10.1016/S1470-2045(18)30415-7.

41. Classen DC, Resar R, Griffin F, Federico F, Frankel T, Kimmel N, et al. 'Global trigger tool' shows that adverse events in hospitals may be ten times greater than previously measured. Health Aff. 2011;30:581-9. https://doi.org/ 10.1377/hlthaff.2011.0190

42. Schildmeijer K, Nilsson L, Perk J, Årestedt K, Nilsson G. Strengths and weaknesses of working with the global trigger tool method for retrospective record review: focus group interviews with team members. BMJ Open. 2013;3:e003131. https://doi.org/10.1136/bmjopen-2013-003131.

43. Von Plessen C, Kodal AM, Anhøj J. Experiences with global trigger tool reviews in five Danish hospitals: an implementation study. BMJ Open. 2012; 2:e001324. https://doi.org/10.1136/bmjopen-2012-001324.

44. Mevik K, Griffin FA, Hansen TE, Deilkås E, Vonen B. Is inter-rater reliability of global trigger tool results altered when members of the review team are replaced? Int J Qual Health Care. 2016;28:492-6. https://doi.org/10.1093/ intghc/mzw054.

45. Earle CC, Ayanian JZ. Looking Back from death: the value of retrospective studies of end-of-life care. J Clin Oncol. 2006;24:838-40. https://doi.org/10. 1200/jco.2005.03.9388.

\section{Publisher's Note}

Springer Nature remains neutral with regard to jurisdictional claims in published maps and institutional affiliations.

Ready to submit your research? Choose BMC and benefit from:

- fast, convenient online submission

- thorough peer review by experienced researchers in your field

- rapid publication on acceptance

- support for research data, including large and complex data types

- gold Open Access which fosters wider collaboration and increased citations

- maximum visibility for your research: over $100 \mathrm{M}$ website views per year

At $\mathrm{BMC}$, research is always in progress.

Learn more biomedcentral.com/submissions 